International Journal of Health Sciences
Available online at www.Sciencescholar.us
Vol. 5 No. 3, December 2021, pages: $605-616$
e-ISSN: 2550-696X, p-ISSN: $2550-6978$
https://doi.org/10.53730/ijhs.v5n3.2618

\title{
Pedagogical Framework for Poly Multicultural Education of Foreign Language Students Seeking a Degree in Teaching
}

\author{
Oksana Chaika a, Nataliya Chahrak b , Marianna Zhumbei c, Halyna Apelt d , Lilia Kopchake, \\ Anastasiia Litvinova ${ }^{f}$
}

Manuscript submitted: 19 July 2021, Manuscript revised: 11 October 2021, Accepted for publication: 24 November 2021

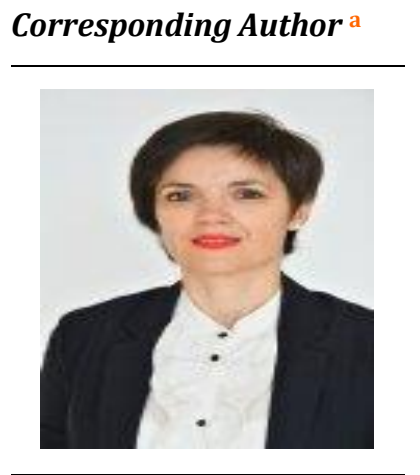

Keywords

educational methodology; educational package; educational process; educational space; multicultural education; pedagogical education; pedagogical framework;

\begin{abstract}
The research aims to explore and establish the ways of creating pedagogical framework for (i) popularizing the idea of poly-/multiculturalism, and (ii) forming relevant students' skills and abilities in foreign language instruction; to determine the extent to which the engaging mentoring teacher in the educating role may influence their poly-/multicultural competence. To this end, poly-/multicultural competence is seen prerequisite of a foreign language teacher's professional competence. Experiment is the main method of the research. Assessment of the experiment effectiveness was carried out with the involvement of surveys/questionnaires, conducted in stages, along with observation as a method applied. The obtained data confirmed the key research hypothesis: the pedagogical framework for the formation of poly-/ multicultural competence with students seeking their bachelor's degree to become teachers of a foreign language connects with mastering two or more foreign languages while intensifying the poly-/multicultural component of education. The main findings result in the contemporary need for formation of a FL teacher's poly-/multicultural competence regarded as the improvement in foreign language proficiency, basic communication skills in a poly-/multiethnic environment, following the proactive positioning of such teacher.
\end{abstract}

International Journal of Health Sciences (C) 2021.

This is an open access article under the CC BY-NC-ND license (https://creativecommons.org/licenses/by-nc-nd/4.0/).

\section{Contents}

Abstract

a National University of Life and Environmental Sciences of Ukraine, Kyiv, Ukraine

b Vasyl Stefanyk Precarpathian National University, Ivano-Frankivsk, Ukraine

c Vasyl Stefanyk Precarpathian National University, Ivano-Frankivsk, Ukraine

d Vasyl Stefanyk Precarpathian National University, Ivano-Frankivsk, Ukraine

e Vasyl Stefanyk Precarpathian National University, Ivano-Frankivsk, Ukraine

f V.N. Karazin Kharkiv National University, Kharkiv, Ukraine 


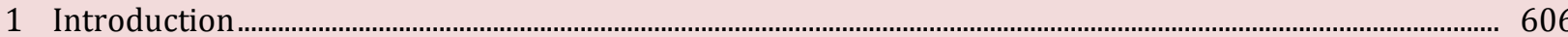

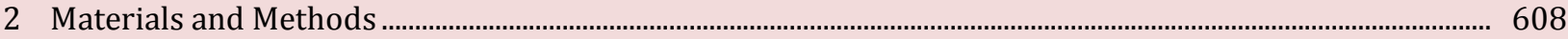

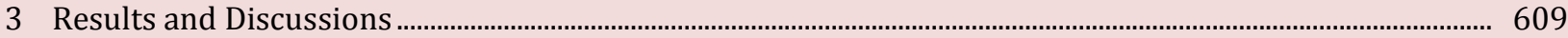

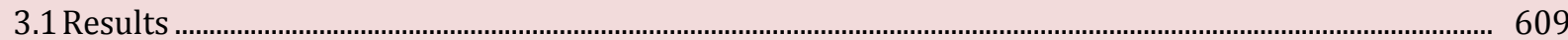

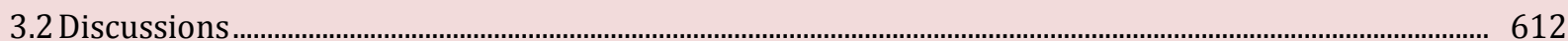

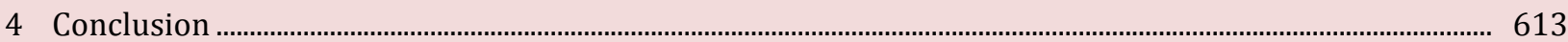

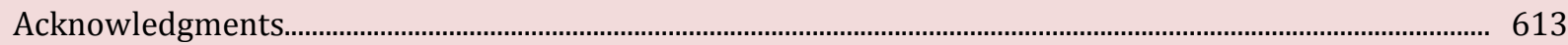

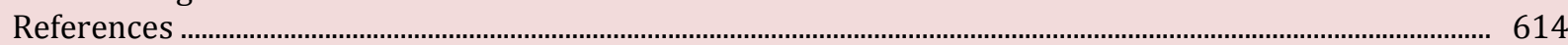

Biography of Authors .................................................................................................................................................... 616

\section{Introduction}

There is a consensus in contemporary pedagogical science as to the need to educate poly-/multiculturalism with future teachers, foreign language teachers, or instructors, in particular (Atkinson et al., 2016). However, that consensus as good practice does not happen to limit any other different views regarding pedagogical approaches and creating a framework that both affect the effectiveness of obtaining poly-/multicultural competence (Fritz et al., 2001). Thus, future foreign language teachers should receive a set of courses during their training, at the beginning and at the end of which the effectiveness of the chosen curriculum and the techniques introduced can be evaluated (Fernández-Manjón et al., 2007). Moreover, tests oftentimes apply to evaluate the educational packages aimed at the effectiveness of poly-/multicultural education. Some studies describe two approaches; one relates to interactive lectures and the other deals with exposure to the experiences of others (Cummins, 2009; Salawali et al., 2021). The mentioned arrives at the need for the unveiling and adopting the pedagogical framework that would best meet the requirements of today's global world (Ruhi, 2016; Ozdamli, 2012). This is believed to outline an urgent scientific and practical objective in the field of contemporary pedagogical thought.

The relevance of the study of poly-/multiculturalism is determined by the diversity, uniqueness, and originality of cultures of modern society (Kusumajaya, 2021). Moreover, in the modern space of communication are many nations different in their languages and cultures, their mindsets, which rigorously interact, remaining special, thus, preserving the unique features of the material and spiritual traditions and culture. The latter as specified leads to fostering multiculturalism rather than polyculturalism. Nevertheless, language and culture tolerance is natural of both - polyculturalism as well as multiculturalism in the expanding cross-border communication plane (Hussin et al., 2021). This factor requires proper consideration and expectation to promote openness and tolerance among representatives of different cultures (Yaschuk, 2014).

The future specialist in the field of teaching foreign languages like no other should be open to dialogue, should be aware of the need for successful interethnic communication in the educational process, the ability to deeply respect and tolerate other cultures, religions, languages, etc. This determines the relevance of developing new methods of fostering poly-/multiculturalism in education as part of professional competence (Koester \& Lustig, 2015; Imahori \& Lanigan, 1989). As demanded by the future profession and reasonable conditions of life in modern society, the need to engage a person in a poly-/multinational community, the ability to cooperate and understand each other have become global requirements. The contemporary public needs to anticipate educational methodologies to look into the professional training of future FL teachers following the humanistic principles (Lomicka \& Lord, 2007; Hedgcock \& Lefkowitz, 1994). Being fully aware of the necessity to determine the pedagogical framework of poly-/multicultural education with the future teacher of foreign languages, it is worth accounting for the role of a teacher in general, and the system of combined curricula, special training courses, and selection of topics dedicated to poly-/multicultural education, in particular (Shirkhani \& Fahim, 2011). Even more, over the past few years, modern pedagogy has witnessed many experimental studies, which led to their integration into the methodological framework, aiming to improve the poly-/multicultural competence of future teachers (Petrović et al., 2015), and FL teachers included. 


\section{Aim and objectives}

The present research findings aim to establish a complex pedagogical framework for poly-/multiculturalism as principal component(s) in the educational space of the poly-/multilingual world. That particularly focuses on the education and training carried out for the professional skills portfolio of future foreign language teachers (Matsuda \& Gobel, 2004). To implement the desired, it is necessary to meet the following objectives:

- To explore as identified the influence of poly-/multicultural competence on the formation of the professional competence in regards to the future foreign language teacher;

- To determine students' evaluation of the teacher in their mentor's role to fostering poly-/multicultural competence as an obligatory component in the structure of a foreign language teacher's professional competence.

\section{Literature review}

Meeting objectives of poly-/multicultural education and pedagogical framework associated with the formation of a professional approach to teaching foreign languages expressly connect to professional and pedagogical competencies (Pope et al., 2019). Therefore, such requires a determined framework for the implementation of curricula that foster and advance poly-/multicultural education (Avery et al., 2007). Thus, the studies conducted (Zhernova, 2018; Mykytiuk et al., 2020), provide a clear description of processes that may lead to increased efficiency in professional training for foreign language teachers, by influencing both the foreign language learning process and the role of the teacher in that process. Pedagogy also considers the concept of 'pedagogical framework'. Husni (2019), specified pedagogical framework as a result of the selection and use of the most effective methods, forms, and contents applicable to achieve a positive result in the learning process.

The pedagogical framework and the burning need to inform/improve poly-/multicultural competence of future specialists in foreign language instruction and training are closely interconnected. The direct relationship between the mentioned encourages to create new opportunities for consideration in the educational space of cultural and cognitive characteristics associated with relevant cultures and traditions, as well as education of tolerant approaches to representatives of different nations, races, religions, etc. (Sleptsova \& Ushnitskaya, 2018).

Much in the research regarding this area (Lee Olson \& Kroeger, 2001), relates to the search for methods and approaches, aiming to prepare professional foreign language teachers with a high level of poly/multicultural competence. This allows to train experts and professionals in the areas of FL instruction and translation, to increase efficiency in linguistic competence of FL teachers, and carry on with teaching foreign languages at a high level (Junining \& Kusuma, 2020; Rababah, 2020). Social media and social networks, in particular, and electronic learning platforms are an important component of intercultural communication (Ashaari, 2018; Lopez et al., 2019). What is also relevant links to the introduction of intercultural activities during the educational process (Matsumoto \& Hwang, 2013); as well as consideration of poly/multilingualism as a sign of modern educational space, the local particulars of poly- / multilingual FL teaching in the educational process (Harding-Esch \& Riley, 2003; Shim \& Lee, 2018). The research literature emphasizes that the ways to achieve high-quality educational services require special attention, focusing on value recognition in connection with educating tolerance of all participants in the educational process (KikiPapadakis \& Chaimala, 2016; Synorub \& Medynska, 2019). Prospective as it is for further research, and would remain, is the design and development of educational and pedagogical complex materials on the education of poly-/multicultural competence and determination of the mentoring teacher's role and influence on the trajectory and progress of poly-/multicultural competence when being formed and established.

Chaika, O., Chahrak, N., Zhumbei, M., Apelt, H., Kopchak, L., \& Litvinova, A. (2021). Pedagogical framework for poly multicultural education of foreign language students seeking a degree in teaching. International Journal of Health Sciences, 5(3), 605-616. https://doi.org/10.53730/ijhs.v5n3.2618 


\section{Materials and Methods}

To study the introduction of pedagogical education, theoretical methods of analysis and synthesis were used, as well accompanied by the descriptive method. Experimenting also sets requirements for the need in empirical methodology. The latter included questionnaires, and the methods of observation and experiment. Statistical methods were applied for the research performance and analysis of data collected, which enabled the team to evaluate the results obtained.

The study adopted a comprehensive approach to the relevant design of the pedagogical framework, which anticipates interactive integrated learning along with the involvement of mentor experience. In the course of the experiment, especially to the beginning and the final stage of the experiment, the achievements of the experimental group (EG) were compared with the results of the control group (CG). This allowed establishing whether or not the pedagogical approach affected the educating process of poly-/multicultural competence of students. In addition, the statistical analysis allowed for investigation of variations and changes in the success of the respondents and the performance of the mentors.

The experiment was conducted at the same time at some universities. These are European higher educational establishments, i.e. Kharkiv National Pedagogical University after Hryhoriy Skovoroda, Ukraine, and Faculty of Foreign Philology, in particular; and a university partner, which is the University of Novi Sad, Serbia, at the Teacher training faculty in the Hungarian language in Subotica.

The experiment lasted one semester of the 2020-2021 academic year in groups of undergraduate students seeking a degree in teaching, foreign language instruction, to be more exact. The students were combined into 2 groups: (i) the control group of 20 respondents, and (ii) the experimental group of 20 respondents. The number totaled 40 students who were foreign language learners. Throughout the experiment, the students in the experimental group were provided with opportunities for thorough poly-/multicultural education under the pedagogical framework. The entire process took place with the agile participation of faculty mentors who provided instruction, education, was in charge of cultural events held at the universities, initiated some more culturally marked university events as out-of-the-classroom activities, and evaluated by measuring students' performance. The control group was taught according to the conventionally adopted curriculum. It is important to note that at the beginning and the end of the experiment the students in the CG also had testing of their performance to their knowledge and skills as professional competence (Zulfija et al., 2013). The specifics and certain difficulties faced by the research team with measuring the students' performance of their poly- / multicultural competence resulted in the need for the below enlisted:

- Design and circulation of the questionnaires, which were introduced at the preparatory and final stages;

- Design and implementation of the content properly structuring learning materials;

- Organization of the learning process as revised; and

- Extracurricular and independent activities of students among the other things.

The questions in the tests were grouped into two sections. Each section contained 25 questions and tasks. According to the results, it became possible to determine and assess the formation levels of poly/multicultural competence and analyze the pedagogical framework that affects the educational process fostering ideas of poly-/multiculturalism under the methodology introduced during the experiment. Calculations were carried out in percentage, which helped identify the formation level of the students' poly-/ multicultural competence, on the one hand. On the other, that allowed evaluating the influence of teachers in their mentor's roles on the respondents when creating and establishing favorable educational conditions under the suggested pedagogical framework.

Students and teachers were involved in the experiment by consent; they voluntarily agreed to participate in the study. The research team of academics prepared all materials for the questionnaires and adhered to the principles of respect and dignity, and confidentiality of participants. No measures were applied in the teaching and learning complex, which may have affected integrity and objectivity with the results and evaluations by the respondents and other engaged participants of the experiment. 


\section{Results and Discussions}

\subsection{Results}

The poly-/multicultural education is complex. Thus, it is found that poly-/multicultural education should contain a set of components. These integrate into the pedagogical framework of teaching, training, and instructing students with the presence of the mentoring teacher and include the content of properly selected and adjusted educational material.

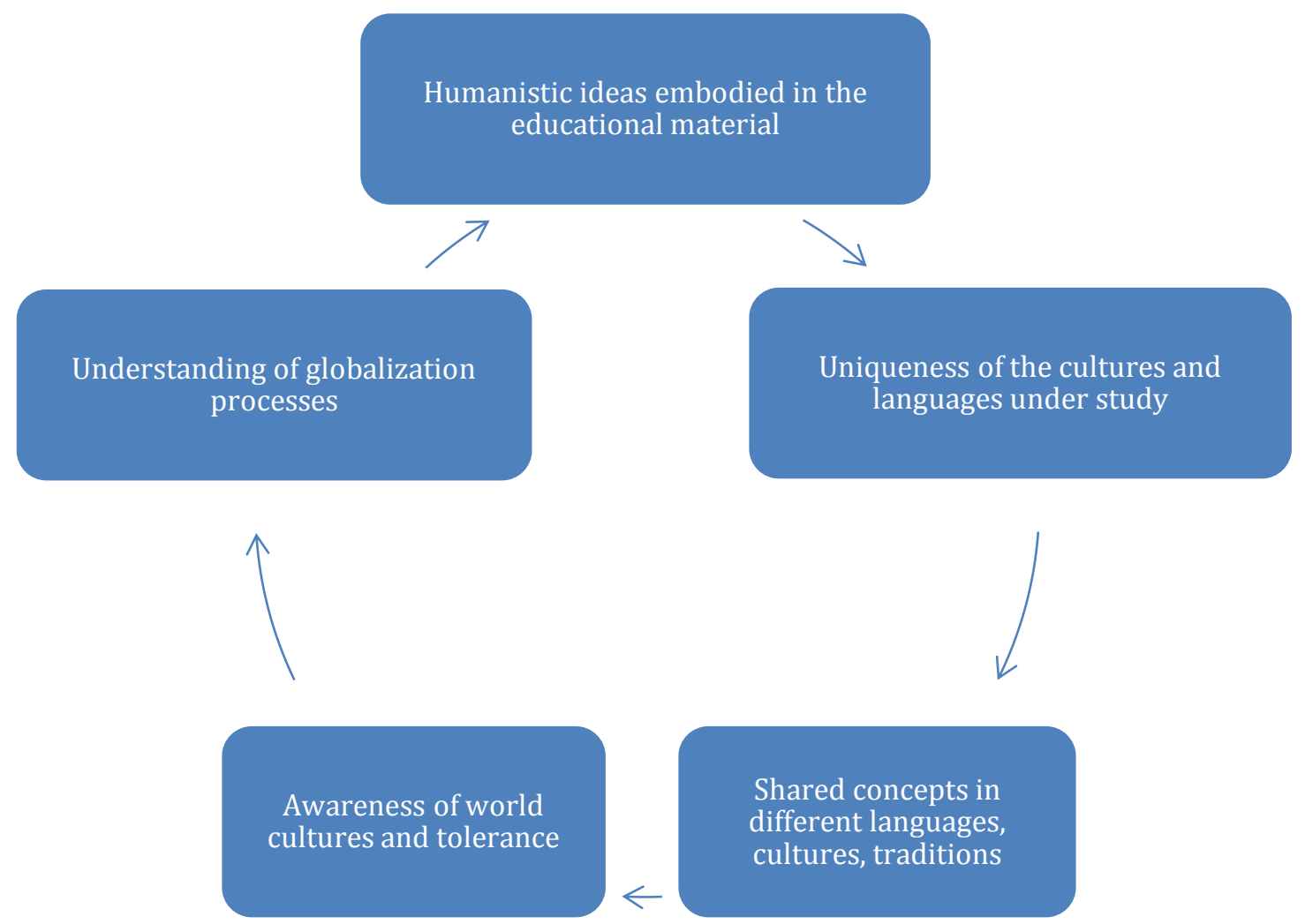

Figure 1. Components in poly- / multicultural education (authors' approach)

The expected result of poly-/multicultural education is the formation of a future teacher's poly-/multicultural competence. This is an important component of professional readiness. It is the foreign language teacher who is the figure that helps and encourages the positive evolution of society, influences the worldview formation of children and youth, is responsible for the formation and cultivation of tolerant views on the interethnic world. In the context of the proposed study, the pedagogical framework acts as a combination of teaching methods, independent performance of students seeking a degree in teaching and FL instruction and foreign language teachers in their mentoring roles, and extracurricular activities aimed at improving the effectiveness of poly/multicultural education in the professional training of future foreign language teachers. Implementation of a set of teaching and educational activities results in the students' mastery in foreign language speaking and instruction at the necessary level of professional and pedagogical competence. The formation of educational and pedagogical complex, aimed at forming and establishing high poly-/multicultural competence, is expressly connected with the (un)favorable conditions of the educational process, including social influence, society, family, financial conditions, etc. Accounting for the described, the experiment relied on a set of conditions deemed favorable and encouraging for the formation of poly-/multicultural competence of students seeking a degree in teaching as future FL instructors.

Chaika, O., Chahrak, N., Zhumbei, M., Apelt, H., Kopchak, L., \& Litvinova, A. (2021). Pedagogical framework for poly multicultural education of foreign language students seeking a degree in teaching. International Journal of Health Sciences, 5(3), 605-616. https://doi.org/10.53730/ijhs.v5n3.2618 


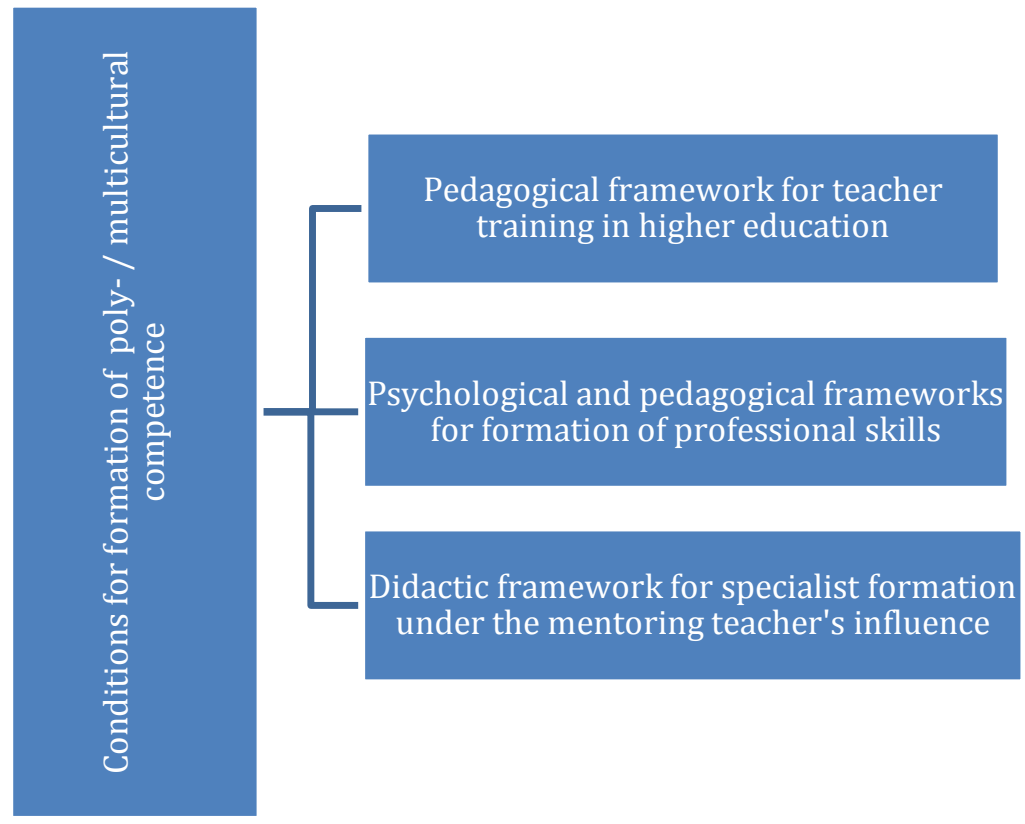

Figure 2. The pedagogical framework of forming poly-/multicultural competence in the educational environment

Mentoring teachers, or teachers in their mentoring roles, at the initial stage of the experiment combined students into two control groups, where Group 1 (CG1) studied according to multi-year curricula. The mentioned curriculum (-a) includes years of teaching two foreign languages without an active extracurricular component and the institute of mentoring. Group 2 (EG2) studied some foreign languages, for example, Hungarian and English were the core subjects while Polish or French were optional. Next, EG2 students were involved in regular extracurricular activities in the field of intercultural communication and had independent creative assignments and projects - group and team projects, on intercultural communication as guided and supervised by mentoring teachers.

Both the groups had the same number of study load in hours. For the experimental group, the preparation stage was two-tier. Firstly, a set of teaching materials was prepared to grow the linguistic and professional competence based on the poly-/multicultural communication component (Dalton et al., 2012; Widana et al., 2021). Secondly, the mentoring teachers had planned meetings for relevant instruction as to the adjusted curriculum of combinatory nature. Under such a curriculum, the mentoring teacher had to perform their traditional role of teaching one of the foreign languages, and at the same time, they had to organize and hold several extracurricular activities and introduce projects, which aimed to establish and cultivate ideas of poly/ multicultural education.

Both the groups took part in testing at the beginning of the experiment and the end of the experiment. The testing part of the experiment anticipated the assessment of current stage knowledge and acquired skills, as well as assessment of the current level of poly-/multicultural competence of the respondents. At the end of the experiment execution, the performance data allowed for measuring, analyzing, and understanding the sufficiency levels of (i) the created pedagogical framework, and (ii) readiness of the mentoring teachers for transferring from traditional to poly-/multicultural education in regards to education, instruction and training of future FL teachers. The research experience acquired during the training helped design and develop an advanced understanding of the form and content of test questions and tasks.

When designing and developing the questions and tasks, the group of researchers relied on the recommendations of the Intercultural Sensitivity Index (ISI). The recommendations of the Department of Education of the Council of Europe served immensely to establish the main criteria for the evaluation of knowledge and skills that guided the study. At the second stage of the experiment, after the first month of training under the experimental program, the survey of students was carried out and the formation level of 
poly-/multicultural competence along with proficiency level in foreign languages under study was determined. The table below presents the results of the assessment regarding the level of poly-/multicultural competence in percentage.

Table 1

Assessment of the students' poly-/multicultural competence (authors' design)

\begin{tabular}{|c|c|c|c|c|c|c|}
\hline \multirow[t]{2}{*}{ \# question unit } & & \multicolumn{3}{|c|}{$\begin{array}{c}\text { Assessment of poly-/multicultural competence } \\
(\%)\end{array}$} & \multicolumn{2}{|c|}{$\begin{array}{l}\text { Number of students } \\
\text { in the group }\end{array}$} \\
\hline & & High & Medium & Low & CG1 & EG2 \\
\hline \multirow[t]{2}{*}{ Question unit 1} & CG1 & 28 & 49 & 23 & 20 & 20 \\
\hline & EG2 & 29 & 50 & 21 & & \\
\hline \multirow[t]{2}{*}{ Question unit 2} & G1 & 28 & 55 & 17 & 20 & 20 \\
\hline & EG2 & 27 & 57 & 16 & & \\
\hline \multirow[t]{2}{*}{ Total } & CG1 & 56 & 104 & 40 & 40 & \\
\hline & EG2 & 56 & 107 & 37 & & \\
\hline
\end{tabular}

At large, the group of mentoring teachers defined the key terms, determined the scope of work and constantly adjusted the content, agreed on the applicable set of methods. The mentioned made the pedagogical framework for education of poly- / multiculturalism in the course of teaching / learning foreign languages at university. It is necessary to note that the main indicators, which are expected to constantly change as improve in the course of the experiment, aim to enable measuring and assessing:

- The level of formation and improvement of poly-/multicultural competence with future FL teachers, and

- The influence of mentoring teachers of higher education on the formation of such students' professional competence.

That is going to lead to creation and implementation of the successfully designed pedagogical framework for poly- / multicultural education, seen as the main factor of verification whether or not testing the teaching and learning complex under study turns effective. At the $3^{\text {rd }}$, and final, stage of testing as to the level of acquired knowledge and skills in the course of doing foreign languages at university, the data once again were collected and analyzed.

Table 2

Assessment of the students' poly-/multicultural competence at the final stage of the experiment (authors' design)

\begin{tabular}{|c|c|c|c|c|c|c|}
\hline \multirow[t]{2}{*}{ № question unit } & & \multicolumn{3}{|c|}{$\begin{array}{l}\text { Assessment of poly- / } \\
\text { multicultural competence (\%) }\end{array}$} & \multicolumn{2}{|c|}{$\begin{array}{c}\text { Number of students in } \\
\text { the group }\end{array}$} \\
\hline & & High & Medium & Low & CG1 & EG2 \\
\hline \multirow[t]{2}{*}{ Question unit 1} & CG1 & 28 & 49 & 23 & 20 & 20 \\
\hline & EG2 & 29 & 50 & 21 & & \\
\hline \multirow[t]{2}{*}{ Question unit 2} & CG1 & 28 & 55 & 17 & 20 & 20 \\
\hline & EG2 & 27 & 57 & 16 & & \\
\hline \multirow[t]{2}{*}{ Total } & CG1 & 56 & 104 & 40 & 40 & \\
\hline & EG2 & 56 & 107 & 37 & & \\
\hline
\end{tabular}

The test results showed that the levels of poly-/multicultural competence and foreign language proficiency improved in the experimental group by overall $8 \%$, and by $3 \%$ in the control group, correspondingly. The final stage of the experiment also determined the role of the didactic component in the process of poly/multicultural education, in particular that of the pedagogical influence of the mentoring teacher's personality

Chaika, O., Chahrak, N., Zhumbei, M., Apelt, H., Kopchak, L., \& Litvinova, A. (2021). Pedagogical framework for poly multicultural education of foreign language students seeking a degree in teaching. International Journal of Health Sciences, 5(3), 605-616. https://doi.org/10.53730/ijhs.v5n3.2618 
on the students' involvement in acquiring and growing the poly-/multicultural competence. The students filled in the questionnaire, which allowed them to evaluate the activities held, the proficiency level of methodological skills in relation to their relevant mentoring teacher in the students' subjective opinions, and the curriculum followed.

Table 3

Performance evaluation of teachers (CG1) and mentoring teachers (EG2) in the education of poly/multiculturalism among the future FL teachers (authors' design)

\begin{tabular}{llll}
\hline $\begin{array}{l}\text { Score } \\
(0-\text { minimum, } \\
12-\text { maximum) }\end{array}$ & Experiment stage & $\begin{array}{l}\text { Evaluation of the } \\
\text { mentoring teacher (EG2) }\end{array}$ & $\begin{array}{l}\text { Evaluation of the FL teacher } \\
\text { (CG1) }\end{array}$ \\
\hline Minimal & Beginning & 6.0 & 6.3 \\
& End & 7.1 & 6.4 \\
Middle & Beginning & 8.3 & 8.6 \\
& End & 8.8 & 9.0 \\
Maximal & Beginning & 10.7 & 10.3 \\
& End & 11.5 & 10.8 \\
\hline
\end{tabular}

Table 3 demonstrates the attitude towards the FL teacher as changing for the better in both the groups during the 1st semester. The experimental group expressed the positive assessment of the FL mentoring teacher's performance, which in general increased by $6 \%$ as opposed to the performance assessment by the control group, which grew only by $3 \%$, correspondingly.

According to the experiment results as to the formation and cultivation of poly- / multicultural competence of students, it was found that FL teachers and FL mentoring teachers influence the learning process and the formation of relevant competencies. The level of FL acquisition while mastering foreign languages in the light of poly- / multiculturalism in the experimental group is higher by $7 \%$ and $5 \%$ in connection to high and medium level estimates, respectively. However, it is lower by $4 \%$ according to the lowlevel estimates.

\subsection{Discussion}

Involving the mentoring teachers makes part of the poly-/multicultural education policy. The policy aims to deliver added educational value to students who seek a degree in teaching and will become future foreign language instructors (Chaika \& Vorotniak, 2021). A group of Eastern European researchers implemented ideas on poly-/multiculturalism, by investigating the formation of professional competence, studying and describing pedagogical framework for tolerance and formation of intercultural communication skills in a poly/multicultural society (Popovych et al., 2020; Jenny, 2017). Besides, several studies (Chatterton \& Goddard, 2000), recommended a valuable approach based on tolerance to solve complex issues of intercultural communication in a more effective way. The study results find that active learning and extracurricular activities, both aiming to acquire poly-/multicultural competence, encourage students for mastery of foreign languages, acquisition of professional knowledge and skills of a FL teacher. The experiment conducted confirmed the importance of such activities for the formation of poly-/multicultural competence of students seeking a degree in teaching for further efficient FL instruction.

Sleptsova \& Ushnitskaya (2018), investigate poly-/multicultural education as a factor in the formation of the future teacher's poly-/multicultural competence and, thus, consider updated models of competence education among students' communities, which reflects the establishing process in the formation of their professional competence. By using Mann-Whitney test, the scholars compare the implementation effectiveness ratio of poly-/multicultural educational framework (Sleptsova \& Ushnitskaya, 2018). Next, the authors find that diagnoses at the beginning and end of the pedagogical experiment result in differences at the level ( $p=0.03-0.08)$ of the following: (a) consciousness changes as to stable and fixed understanding of a foreign language, (b) awareness of the culture value, and (c) self-identification as a representative of a certain national (ethnic) community. 
The experimental study discussed validated the utter importance of poly-/multicultural competence in teaching foreign languages to students and engagement of the mentoring teachers in the educational process. It is stated under the research findings that ideas of poly-/multiculturalism on the equality of religions, languages, cultures should be part of the FL teacher's professional training. This is driven from the results represented in the evaluation by the groups of students of the mentors' performance. In general, the positive attitude towards the performance of the mentoring teacher increased in the semester by $8 \%$. To summarize, it is worth carrying on with development of favorable pedagogical framework, educational and pedagogical complexes with poly-/multicultural educational component to teach and train future foreign language specialists.

\section{Conclusion}

The experiment shows that the introduction of the favorable pedagogical framework based on the properly selected educational and pedagogical complex includes the poly-/multicultural educational component, on the one hand. On the other, it helps advance more effective ways for FL instruction, provides means of successful intercultural communication, grows knowledge-based professional competencies along with the acquired skills for FL instruction and training of future specialists in foreign language teaching. According to the results of the final test, the level of poly-/multicultural competence and foreign language proficiency improved by average $8 \%$ and $3 \%$ with the experimental and control groups, correspondingly.

The introduction of poly-/multicultural education in higher education also contributes to the teacher's effective performance in the formation of students' poly-/multicultural competence in general. That will provide high quality education for the philology students. That will allow performing better in the plane of tolerant and humanistic intercultural policy. Overall, the students who participated in the experiment positively evaluated the introduction of poly-/multicultural educational component, as well as the active involvement of a mentoring teacher. The described emphasizes the increased value of the mentoring teacher's role in the course of poly-/multicultural education of future FL teachers.

Finally, it appears crucial to consider the educational environment in the new light of the fast pacing and rapidly changing societies. The contemporary world is demanding, which stipulates higher educational establishments and institutions design, develop and implement curricula that intensify quality of education with the poly-/multicultural component for more efficient and productive intercultural communication, enhance the role of the mentoring teacher in foreign language instruction and professional training. The foreign language teachers may actively use the process of education for internationalization, improve the overall quality of teaching and learning in foreign language classrooms, and make it more modern and engaging. The research findings disclose the burning need of the global community in bringing the higher education to the new heights by means of wide acceptance and implementation of the principles based on poly-/multiculturalism.

The perspective ideas for further study may relate to cross-border collaboration between academics and universities in order to design the unified approach to implementation of the favorable pedagogical framework, which would internationally facilitate the teaching and learning processes of foreign languages and improve the communicative skills of future foreign language specialists in the context of educational globalization.

Acknowledgments

We are grateful to two anonymous reviewers for their valuable comments on the earlier version of this paper.

Chaika, O., Chahrak, N., Zhumbei, M., Apelt, H., Kopchak, L., \& Litvinova, A. (2021). Pedagogical framework for poly multicultural education of foreign language students seeking a degree in teaching. International Journal of

Health Sciences, 5(3), 605-616. https://doi.org/10.53730/ijhs.v5n3.2618 


\section{References}

Ashaari, S. (2018). Quantifying user experience in using learning gamification website. Journal of Theoretical and Applied Information Technology, 96(23).

Atkinson, D, Byrnes, H, Doran, M, Duff, P, Ellis, NC, Hall, JK, \& Tarone, E. (2016). A transdisciplinary framework for SLA in a multilingual world. Modern Language Journal.100, 19-47.

Avery, D. R., Tonidandel, S., Thomas, K. M., Johnson, C. D., \& Mack, D. A. (2007). Assessing the Multigroup Ethnic Identity Measure for measurement equivalence across racial and ethnic groups. Educational and Psychological Measurement, 67(5), 877-888.

Chaika, O., \& Vorotniak, L. (2021). Poly-/Multiculturality in Higher Education: Methodological Level of the Research Concept.

Chatterton, P., \& Goddard, J. (2000). The response of higher education institutions to regional needs. European Journal of Education, 35(4), 475-496.

Cummins, J. (2009). Multilingualism in the English-language classroom: Pedagogical considerations. TESOL quarterly, 43(2), 317-321.

Dalton, M., Davidson, M., \& Keating, J. L. (2012). The assessment of physiotherapy practice (APP) is a reliable measure of professional competence of physiotherapy students: a reliability study. Journal of physiotherapy, 58(1), 49-56. https://doi.org/10.1016/S1836-9553(12)70072-3

Fernández-Manjón, B., Sánchez-Pérez, J. M., Gómez-Pulido, J. A., Vega-Rodríguez, M. A., \& Bravo-Rodríguez, J. (Eds.). (2007). Computers and education: E-learning, from theory to practice. Springer Science \& Business Media.

Fritz, W., Mollenberg, A., \& Chen, G. M. (2001). Measuring Intercultural Sensitivity in Different Cultural Context.

Harding, E., Harding-Esch, E., \& Riley, P. (2003). The bilingual family: A handbook for parents. Cambridge University Press.

Hedgcock, J., \& Lefkowitz, N. (1994). Feedback on feedback: Assessing learner receptivity to teacher response in L2 composing. Journal of second language writing,3(2), 141-163. https://doi.org/10.1016/10603743(94)90012-4

Husni, H. (2019). Moderate Muslims' Views On Multicultural Education, Freedom Of Expression, And Social Media Hate Speech: An Empirical Study In West Java Indonesia. Jurnal Penelitian Pendidikan Islam, 7(2), 199-224.

Hussin, D. A., Samah, M. A. A., Suhaimi, A. A., \& Kamarudin, M. K. A. (2021). A study on knowledge, attitude and practice of COVID-19 pandemic among the residents. International Journal of Health Sciences, 5(2), 177 188. https://doi.org/10.29332/ijhs.v5n2.1378

Imahori, T. T., \& Lanigan, M. L. (1989). Relational model of intercultural communication competence. International Journal of Intercultural Relations, 13(3), 269-286. https://doi.org/10.1016/0147-1767(89)90013-8

Jenny, W. A. N. G. (2017). Cloud computing technologies in writing class: Factors influencing students' learning experience. Turkish Online Journal of Distance Education, 18(3), 197-213.

Junining, E., \& Kusuma, V. (2020). Translation strategies for translating a news article. LiNGUA, 15(1).

Kiki-Papadakis, K., \& Chaimala, F. (2016). The Embedment of Responsible Research and Innovation Aspects in European Science Curricula. Romanian Journal for Multidimensional Education/Revista Romaneasca Pentru Educatie Multidimensionala, 8(2).

Koester, J., \& Lustig, M. W. (2015). Intercultural communication competence: Theory, measurement, and

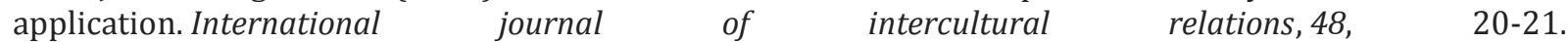
https://doi.org/10.1016/j.ijintrel.2015.03.006

Kusumajaya, A. A. N. (2021). Individual and social environmental factor as risk factor of BMI-for-age in school children. International Journal of Health Sciences, 5(2), 89-98. https://doi.org/10.29332/ijhs.v5n2.1242

Lee Olson, C., \& Kroeger, K. R. (2001). Global competency and intercultural sensitivity. Journal of studies in international education, 5(2), 116-137.

Lomicka, L., \& Lord, G. (2007). Social presence in virtual communities of foreign language (FL) teachers. System, 35(2), 208-228. https://doi.org/10.1016/j.system.2006.11.002

Lopez, M. M. L., Herrera, J. C. E., Figueroa, Y. G. M., \& Sanchez, P. K. M. (2019). Neuroscience role in education. International Journal of Health \& Medical Sciences, 3(1), 21-28. 
Matsuda, S., \& Gobel, P. (2004). Anxiety and predictors of performance in the foreign language classroom. System, 32(1), 21-36. https://doi.org/10.1016/j.system.2003.08.002

Matsumoto, D., \& Hwang, H.C. (2013). Assessing Cross-Cultural Competence: A Review of Available Tests. Journal of Cross-Cultural Psychology. 44, 849-873.

Mykytiuk, S., Lysytska, O., \& Melnikova, T. (2020). Facebook Group as an Educational Platform for Foreign Language Acquisition. Postmodern Openings/Deschideri Postmoderne, 11.

Ozdamli, F. (2012). Pedagogical framework of m-learning. Procedia-Social and Behavioral Sciences, 31, 927931. https://doi.org/10.1016/j.sbspro.2011.12.171

Petrović, D. S., Starčević, J., Chen, G. M., \& Komnenić, D. (2015). Intercultural sensitivity scale: Proposal for a modified Serbian version. Psihologija, 48(3), 199-212.

Pope, R. L., Reynolds, A. L., \& Mueller, J. A. (2019). Multicultural competence in student affairs: Advancing social justice and inclusion. John Wiley \& Sons.

Popovych, V., Ragimov, F., Kornienko, V., Ivanova, I., \& Zoriana, B. (2020). Development of social and communicative paradigm of public administration in the field of social networks. International Journal of Data and Network Science, 4(3), 319-328.

Rababah, I. H. M. (2020). The Reality of Using Modern Teaching Methods in Teaching Arabic for Speakers of other Languages from Teachers' Perspective. Journal of Social Sciences (COES\&RJ-JSS), 9(1), 58-94.

Ruhi, U. (2016). An experiential learning pedagogical framework for enterprise systems education in business schools. The International Journal of Management Education,14(2), 198-211. https://doi.org/10.1016/j.ijme.2016.04.006

Salawali, A. Q. ., Tahir, A. M. ., \& Hardjo, M. . (2021). The effect of family education on the fulfillment of family health tasks in handling case of hypertension post earthquake in Sigi regency. International Journal of Health \& Medical Sciences, 4(1), 136-140.

Shim, H., \& Lee, S. (2018). Development of educational materials using Prezi as digital storytelling tool. Journal of Theoretical and Applied Information Technology, 96(22), 7491-7499.

Shirkhani, S., \& Fahim, M. (2011). Enhancing critical thinking in foreign language learners. Procedia-Social and Behavioral Sciences, 29, 111-115. https://doi.org/10.1016/j.sbspro.2011.11.214

Sleptsova, G., \& Ushnitskaya, V. (2018). Multicultural Education as a Factor of Formation of Cross-Cultural Competence among Bachelors-Teachers. NORDSCI.

Synorub, H., Medynska, O. (2019). Development of information culture of students of humanitarian specialities. Information Technologies and Learning Tools. 72(4), 152-167.

Widana, I.K., Sumetri, N.W., Sutapa, I.K., Suryasa, W. (2021). Anthropometric measures for better cardiovascular and musculoskeletal health. Computer Applications in Engineering Education, 29(3), 550561. https://doi.org/10.1002/cae.22202

Yaschuk, S. (2014). Pedagogical conditions of forming professional and pedagogical competence in future technological education masters. The Advanced Science Journal. 11, 23-27.

Zhernova, A. (2018). Information and communication technologies in higher education: toward the preparedness of the subjects of education for innovation. Scientific Research in Social and Political Psychology, 33, 172-179.

Zulfija, M., Indira, O., \& Elmira, U. (2013). The professional competence of teachers in inclusive $\begin{array}{llll}\text { education. Procedia-social and behavioral 549-554. } & \text { sciences, 89, }\end{array}$ https://doi.org/10.1016/j.sbspro.2013.08.892

Chaika, O., Chahrak, N., Zhumbei, M., Apelt, H., Kopchak, L., \& Litvinova, A. (2021). Pedagogical framework for poly multicultural education of foreign language students seeking a degree in teaching. International Journal of Health Sciences, 5(3), 605-616. https://doi.org/10.53730/ijhs.v5n3.2618 


\section{Biography of Authors}

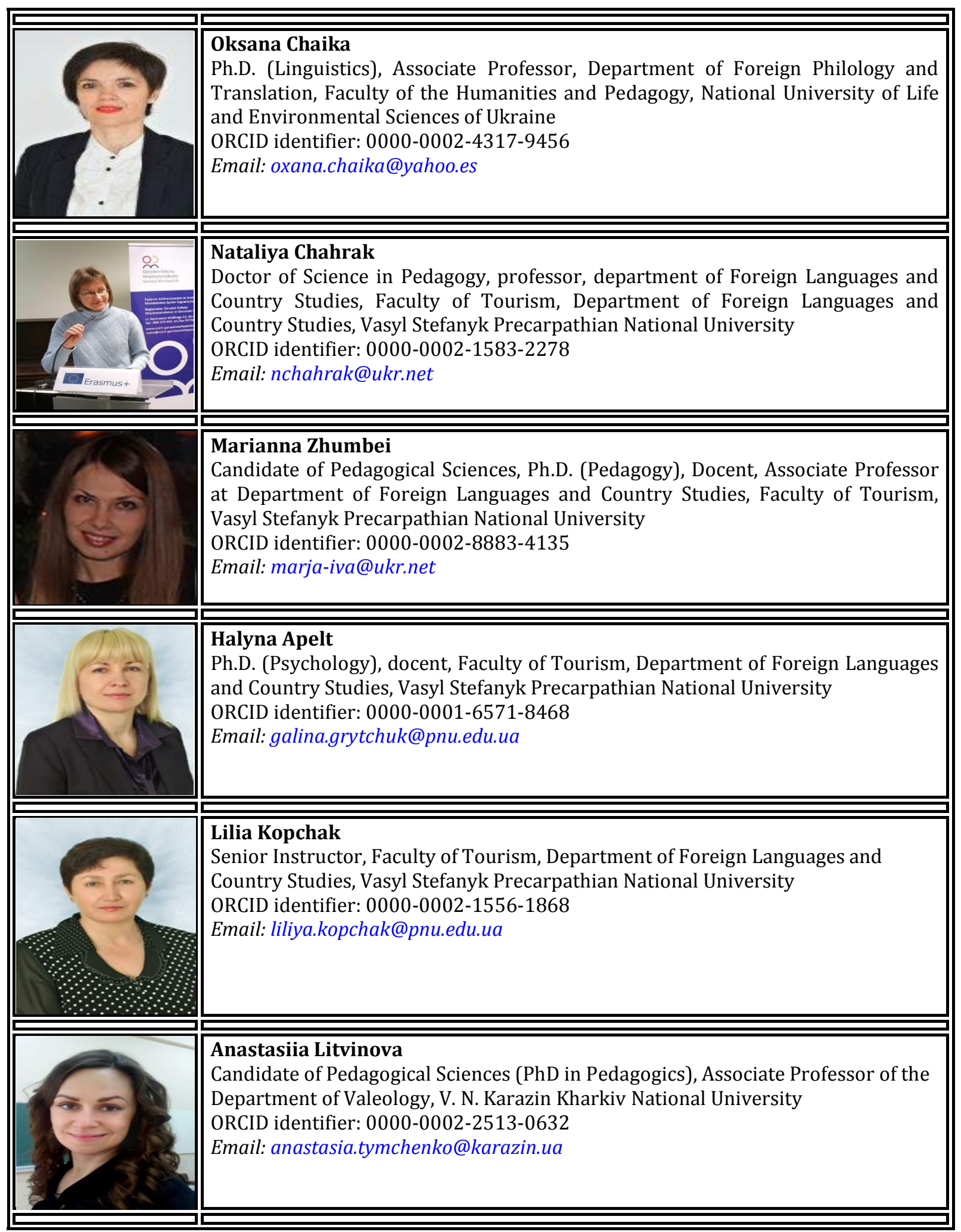

